\title{
Fundamental Study on the Development of Sprayed High Performance Fiber Reinforced Cementitious Composites for Impact-Blast Resistant
}

\author{
Yun-Wang Choi ${ }^{1}$, Man-Seok Park ${ }^{2}$, Byung-Keol Choi ${ }^{3}$, and Sung-Rok $\mathrm{Oh}^{4}$
}

\begin{abstract}
In the recent concrete industry, high fluidity concrete is being widely used for the pouring of dense reinforced concrete. Normally, in the case of high fluidity concrete, it includes high binder contents, so it is necessary to replace part of the cement through admixtures such as fly ash to procure economic feasibility and durability. This study shows the mechanical properties and field applicability of high fluidity concrete that using mass of fly ash as alternative materials of cement. The high fluidity concrete mixed with $50 \%$ fly ash was measured to manufacture concrete that applies low water/binder ratio to measure the mechanical characteristics as compressive strength and elastic modulus. Also, in order to evaluate the field applicability, high fluidity concrete containing high volume fly ash was evaluated that fluidity, compressive strength, heat of hydration and drying shrinkage of concrete.
\end{abstract}

Keywords: high volume fly ash, high fluidity concrete, early strength, field application

${ }^{1}$ Dept. of Civil Engineering, Semyung University, Jecheon 390-711, Korea

E-mail: crete77@semyung.ac.kr

${ }^{2}$ Dept. of Civil Engineering, Semyung University, Jecheon 390-711, Korea

E-mail: sogech@nate.com

${ }^{3}$ Dept. of Civil Engineering, Semyung University, Jecheon 390-711, Korea

E-mail:smlcbk@nate.com

${ }^{4}$ Dept. of Civil Engineering, Semyung University, Jecheon 390-711, Korea

E-mail: cgdbs02@nate.com 


\section{Introduction}

Recently, the demand of the safety of stability of the concrete structures against the terrorism and explosion casualties has been desperately increased in the societies in accordance with the increased risks to the social infrastructures and private facilities other than the military defense facilities which are directly exposed to the extreme external forces caused by the ceaseless occurrences of the terrorism and explosion casualties in domestic and foreign countries.

In this regard, the studies on the cement composite materials reinforced with high-performance fiber to the cement composites (HPFRCCs) are actively progressed domestically and internationally, to prevent the brittle failure of the concrete which has relatively very low tensile strength and critical tensile strain than compressive strength as well as to improve tensile behavior as well as energy dissipation capacity. $[1,2,3,4,5]$

However, researches on materials and materials that configures of the effective safety protection and explosion-proof for the social infrastructures and private facilities are insufficient yet. In addition, different from newly built structures, the researches on the high-performance composite materials and its application technologies are required to maximize the reinforcing performance preparing for the safety protection and explosion-proof in the limited sizes, for the existing structures being used.

On the other hand, the technologies for the composite materials for the safety protection and explosion-proof reinforcement of the existing structures may be classified into the spray-coating type, external layer type and panel type depending upon the applied technologies, and in particular, it is reported that the composite materials of spray-coating type has a very important issue how to control the different flow characteristics required at each of the construction steps.[6]

That is; during the materials moving to the nozzle via a hose by the spray-coating pump, it is required of low viscosity easy to pump under pressure, and after being sprayed to the placement area through a nozzle by the high-pressure air spray, a high viscosity shall be expressed and maintained of the attachment with the placement area and the integrity of materials.[7] In addition, it is required that the quantitative analysis on the effective factors of various composite materials primarily used for the spray-coating type composite materials shall be conducted in order to develop the quality and control technologies on the spray-coating type composite materials specializing in the safety protection and explosion-proof reinforcement system. 
Accordingly, this paper represents the assessments of rheological properties without fiber mixed at the paste and mortar step as well as the rheological and mechanical properties at HPFRCCs step with fiber mixed, in the line of basic researches to develop the spray-coating HPFRCCs reinforced with the safety protection and the explosion-proof for the existing structures.

\section{Experiment Overview}

\subsection{Materials used}

\subsubsection{Binder}

Binders were used with the ordinary Portland cement(OPC), a fly ash(FA), a ground granulated blast-furnace slag(GGBFs) and a silica fume(SF). Table 1 shows the chemical composition and physical properties of the binder used in this experiment.

\subsubsection{Aggregate}

Aggregates were used with the standard sand specified in ISO 679 (ASTM C 778), 60 150 mesh of more than 95\% SiO2 \# 7 silica sand, river sand of the Nakdong river, sea sand of the Incheon and crushed sand of the Joocheon. Table 2 shows the physical properties of the used aggregates. Also, for the particle size adjustment, \#2 \#7 silica sand were used.

\subsubsection{Fiber}

Fiber was used length $8 \mathrm{~mm}$, diameter $39 \mu \mathrm{m}$ of Japanese K company's polyvinyl alcohol (PVA). Table 3 presents the physical properties of the fiber.

\subsubsection{Chemical Admixture}

Chemical admixtures were used with high performance polycarboxylate water-reducing agent (SP) and solid contents of $24 \sim 25 \%$ liquid-type urethane viscosity agent (VA).

\subsection{Experimental Method}

\subsubsection{Experimental Design and mixture proportions}

In the paste phase, we conducted the paste blending using $50 \%$ of water-binder ratio (W/B) of 
OPC, FA, GGBFs and SF as $100 \%$ each of binders in order to assess the rheological properties by binder type. We also conducted the paste blending equally using SP $0.5 \%$ (binder mass $\mathrm{x} \%$ ) with mixtures of FA 3 levels (10\%, 20\% and 30\%), GGBFs 3 levels (15\%,30\% and 45\%) and SF 3 levels $(5 \%, 10 \%$, and $15 \%)$ against OPC volume in the reference paste formation using W/B 35\% of POC as a $100 \%$ binder in order to assess the rheological properties depending upon the mixed rates of binders.

In the mortar phase, we conducted the mortar blending using standard sand, \#7 silica sand, river sand, sea sand and crushed sand as a 100\% aggregate respectively in the formation using W/B 35\%, fine aggregate-mortar volume ratio $40 \%$ (hereinafter referred to as Vs/Vm), SP $0.5 \%$ and OPC as a $100 \%$ binder respectively in order to assess the rheological properties depending upon the by type of fine aggregate. Also, we performed the mortar blending using $100 \%$ of selected silica sands of \#7 levels (F.M. 1.80, 1.95, 2.32, 2.69, 3.06, 3.43, 3.61) adjusted the particle size by using \#2 7 silica sands in the formation which used the W/B 35\%, Vs/Vm 40\%, SP 0.5\%\% and OPC as the $100 \%$ binders in order to assess the rheological properties depending upon the fine aggregate particle size.

In the HPFRCCs phase, in the reference formation using W/B 34\%, Vs/Vm 36\% and OPC and \#7 silica sands as $100 \%$ of a binder and an aggregate, we conducted HPFRCCs blending by admixing PVA fiber 2\% (Vol. x\%) after mixing SP 5 levels (0.3\%, 0.6\%, 0.9\%, 1.2\% and 1.5\%) and VA 5 levels $(0.2 \%, 0.4 \%, 0.6 \% 0.8 \%$ 哭 $1.0 \%)$ in order to assess the liquidity, rheological properties and mechanical properties depending upon the consumption amount of chemical admixture.

Table 4 illustrates the summarized experimental parameters and the assessment items in accordance with each phase.

\subsubsection{Rheological test}

Regarding the rheological test on the paste, Brookfield Corporation's viscometer was used for the paste DV- $I$ Pro model as shown in Fig. 1 (a), and on the mortar and HPFRCCs, the mortar viscometer modified the chamber size of Brookfield Corporation's DV-III Ultra model mortar viscometer was used as shown on Fig. 1(b) to assess the amount of change in the Shear stress in accordance with Shear rate. In addition, to avoid the hysteresis of the assessment value by the hysteresis loop area as shown on Fig. 2(a), the shear rate was set and assessed in the cascade type and, through the linear regression analysis on the measured shear stress, interpreted in the 
Bingham model as Fig. 1(b) to assess the plastic consistency and the yield stress.

\subsubsection{Fluidity test}

Fluidity test was conducted by using the flow table specified in ASTM C 230 and in accordance with ASTM C 1437.

\subsubsection{Compressive strength test}

Compressive strength test was performed in accordance to ASTM C 109. After producing $50 \times$ $50 \times 50 \mathrm{~mm}$ test specimen, we performed air-dry curing on them for 24 hours and then demolded them to do the standard curing in the curing water tank which kept $20 \pm 2^{\circ} \mathrm{C}$, and estimated the compressive strengths of the test specimen passing 3 days, 7 days and 28 days respectively.

\subsubsection{Bending Performance test}

Bending performance test was conducted in accordance with ASTM C 1609. After producing $100 \times 100 \times 400 \mathrm{~mm}$ test specimen, we performed air-dry curing on them for 24 hours and then demolded them to do the standard curing in the curing water tank which kept $20 \pm 2^{\circ} \mathrm{C}$, and estimated the bending performance of the specimen. Fig 3 shows the measuring device for bending performance.

\section{Results and discussions}

\subsection{Paste stage}

In order to evaluate the effect factors of the composite materials in the paste phase that was not admixed with fiber, we assessed the rheological properties by composite type and the rheological properties in accordance with the mixing rates of binder materials used in HPFRCCs.

\subsubsection{The rheological properties depending upon the types of binders}

Fig 4 represents the evaluated rheological properties depending upon the types of binders.

As a result of Fig 4, the plastic viscosity and the yield stress were shown in the order of OPC > FA > GGBFs, and the range of the plastic viscosity were found $0.13 \sim 0.39$ Pa.s, that of the yield stress were $0.42 \sim 1.79 \mathrm{~Pa}$. 
On the other hand, in case of SF, as it was not mixed in the formulation planned in this study, the rhetological assessment was not available, of which reason was judged that W/B was not mixed under the same condition as the binding force of water became strong due to the large specific surface area of SF.

3.1.2 Rheological properties in accordance with the mixing rates of binders

Table 5 shows the evaluation of the rheological properties depending upon the mixing rates of the binders.

As a result of Table 5,

in cases of FA and GGBFs, the plastic viscosity and the yield stress have been decreased in accordance with the increase of the mixing rates and, in case of SF, the plastic viscosity and the yield stress are sharply increasing from $10 \%$ of admixture rate. This result was considered that, in case of FA, as most of particle forms were spherical, the plastic viscosity and the yield stress may be decreased in accordance with the increase of mixing rate due to the ball bearing effect, and in case of GGBFs, it is determined that the plastic viscosity and the yield stress have been decreased in accordance with the increase of the mixing rate as the surface of particles is amorphous and glassy and has the structure not to absorb water well and the characteristics having zeta-potential stability more than OPC and FA. Meanwhile, in case of SF, as mentioned before, as the specific surface area is approximately 50 times larger compared to FA and GGBFs, as the area where the particles can contact water is increasing and accordingly the binding force of water becomes stronger, the plastic viscosity and the yield stress is determined to increase in accordance with the increase of the mixing rate.

Fig 5(a) and 9(b) represents the correlation between the plastic viscosity and the yield stress in accordance with the mixing rates of binders. As a result of Fig 5 (a) and (b), the correlation coefficient $r$ of the plastic viscosity and the yield stress in accordance with the increase of mixing rate of binders shows respectively -1.00 and -0.99 in case of FA, -1.00 and -0.98 in case of GGBFs, and 0.92 and 1.00 in case of SF. Through such results, it is considered that the increase and decrease of the plastic viscosity and the yield stress in accordance the mixing rate of binders may be valid.

\subsection{Mortar phase}

In order to evaluate the influence factor of the aggregate in the mortar phase without mixing fiber, we assessed the rheological properties in accordance with type of the composite materials 
used for HPFRCCs and the rheological properties in accordance with the particle sizes of aggregates.

\subsubsection{Rheological properties by type of aggregates}

Fig 6 is shown by evaluating the rheological properties by type of aggregates. As a result of Fig 6, the plastic viscosity and the yield stress are shown in the order of crushed sand>sea sand>river sands>standard sand, and the range of the plastic viscosity is as $1.75 \sim 3.03$ Pa.s, and the yield stress is as $111.73 \sim 28.51 \mathrm{~Pa}$. In case of crushed sands, its plastic viscosity and the yield stress is shown the greatest, and in cases of standard sand and silica sand, their plastic viscosity and the yield stress are shown relatively small. Through such results, it is regarded that the type of aggregates may have a significant influence on the plastic viscosity and the yield stress.

\subsubsection{The rheological properties of the aggregate size}

Table 6 is shown by evaluating the rheological properties of the aggregate sizes. As a result of Table 6, the plastic viscosity and the yield stress shall be decreased in accordance with the increase of the assembly rate.

Fig. 7 (a) and (b) presents the correlation between the plastic viscosity and the yield stress in accordance with the particle sizes of aggregates. As a result of Fig 7(a) and (b), the correlation coefficient $r$ of the plastic viscosity and the yield stress in accordance with the increase of the assembly rate shows respectively -1.00 and -1.00 . Through such results, it is considered that the increase and decrease of the plastic viscosity and the yield stress in accordance the particle sizes so called the assembly rate - of aggregates may be valid.

\subsection{HPFRCCs phase}

In order to assess the influence factors of the composite materials in the HPFRCCs phase admixing fiber, we assessed the liquidity, rheological properties and mechanical properties in accordance with the amount of chemical admixtures used for HPFRCCs.

\subsubsection{Liquidity}

Fig. 8 (a) and (b) are represented by evaluating the liquidity in accordance with the amount of chemical admixtures used. As a result of Fig 8(a), in case of increasing the usage of SP after admixing fiber to the reference mixture without admixing fiber, the liquidity showed greatly decreased as the fiber ball phenomena was significantly taking place after admixing fiber amount. In addition, though the liquidity was shown as somewhat increasing depending upon the increase 
of the amount of SP used, however, the material segregation occurred from $1.5 \%$ of dose, and it was shown that the fiber ball phenomena was not improved and there was no effect of fiber dispersion even though the SP dose was increased by approximately 4 times compared to the reference mixture without admixing fiber.

As a result of Fig $8(b)$, in case of fixing the SP dose in the reference mixtures without admixing fiber and increasing the VA dose after admixing fiber, it shows that the fiber ball phenomena after admixing fiber occurred and its liquidity was sharply decreased, however, in accordance with the increase of the VA dose, it was shown that the fiber ball phenomena was gradually improved and the liquidity was increased. In addition, it was shown the material segregation phenomena did not occurred. At $1.0 \%$ of VA dose, the equal level of liquidity was shown compared to the reference mixture without admixing fiber, and it was shown that the fiber ball phenomena was completely improved and the fiber dispersion was secured. Such results were determined that as it was known that, if we generally use $\mathrm{SP}$, it was the most effective to improve the liquidity of matrix, however, if we use SP too much, the viscosity of matrix became low and there was a characteristic to make the material segregation phenomena easy, it is judged that the material segregation and fiber ball phenomena occurred. In addition, as it was known that, if we generally use VA, the liquidity of matrix, the liquidity of matrix might be somewhat decreased but there was a characteristic to increase the viscosity with relatively ease, the fiber ball phenomena was improved and the fiber dispersion was secured.

\subsubsection{Rheological properties}

Fig 9(a) and (b) are represented by evaluating the rheological properties in accordance with the chemical admixture doses. As a result of Fig 9(a), in case of increase the SP dose after admixing fiber into the reference mixture without admixing fiber, it was shown that at $0.9 \%$ of SP dose, the plastic viscosity was decreased and the yield stress was increased compared to the reference mixture without admixing fiber, and at $1.2 \%$ of SP dose, the plastic viscosity and the yield stress were somewhat increased compared to $0.9 \%$ of SP dose. Such result is judged due to the fiber ball phenomena shown as Fig 8(a). In addition, from 1.5\% of SP dose, the plastic viscosity and the yield stress were gradually decreased compare to $1.2 \%$ of SP dose. The reasons of such result are considered due to the material segregation and fiber ball phenomena shown as Fig 8(a).

As a result of Fig 9 (b), in case of fixing the SP dose in the reference mixture without admixing fiber and increasing the VA dose after admixing fiber, there showed the tendencies that the fiber ball phenomena occurred and the plastic viscosity was decreased and the yield stress was 
increased at $0.2 \%$ of VA dose shown as Fig $8(\mathrm{~b})$, however, from $0.4 \%$ of VA dose, there showed the tendencies that the plastic viscosity and the yield stress were increased, and from $0.8 \%$ of VA dose, there showed the plastic viscosity and the yield stress were decreased and became the equal levels of the plastic viscosity and the yield stress compared to the reference mixture without admixing fiber. Such results are considered to show the fiber dispersion was gradually improved in accordance with the increase of the amount of the VA usage.

\subsubsection{Mechanical properties}

Fig. $10(a)$ and (b) is shown by evaluating the compressive strength properties of the chemical mixture dose.

As a result of Fig 10 (a), the compressive strengths of aging 3 days, 7 days, and 28 days were somewhat decreased depending upon the increase of the SP doses, however, they were shown less than $5 \%$ of tolerance. Such results are considered due to the material segregation and the fiber ball phenomena shown as Fig 8(a), and also determined there showed no changes on the compressive strengths albeit the material segregation, as the balled fiber in the matrix physically reacted due to the fiber ball phenomena during measuring the compressive strengths. Such results are considered to show the fiber dispersion was gradually improved in accordance with the increase of the amount of the VA usage.

As a result of Fig $10(\mathrm{~b})$, all the compressive strengths of aging 3 days, 7 days and 28 days were decreasing in accordance with the increase of the VA doses. Such results are determined that as it was known that there was a characteristic to delay the solidity of matrix and occurred a large amount of microbubbles which were to lower the strength, if we do not generally use VA, it is judged that the strengths would be decreased in accordance with the increase of the VA doses.

Through such results, it is judged that SP would not impact the strength, and, in case of VP, as the increase of dose would decrease the strength, we should supplement the strength by using the deformer agents.

Fig 11 (a) and (b) is shown by evaluating the compressive strength properties in accordance the doses of chemical mixtures.

As a result of Fig 11(a), it is shown that the bending strength at aging 28 days was increased in accordance with the increase of the SP dose, and even though the toughness in accordance with 
the fiber admixing depending upon the increase of the VA dose was somewhat increased, however, there shows no significant effect. Such results are judged due to the material segregation and the fiber all phenomena shown as Fig 8(a), and it is considered that the toughness increase effect in accordance with admixing fiber was not shown as the fiber dispersion was dropped due to the fiber ball phenomena.

As a result of Fig 11(b), it was shown that the bending strength at aging 28 days was increased in accordance with the VA doses, and in accordance with the increase of the VA doses, the toughness was increased in accordance with the admixture of fiber, and showed the behavior of strain hardening at $0.8 \%$ and $1.0 \%$ of the VA doses. Such results are judged that the toughness increase effect was shown in accordance with the fiber mixture due to the secured fiber dispersion through the improvement of the fiber ball phenomena in accordance with the increase of the VA doses shown as Fig 8(b).

\section{Conclusion}

In the line of basic study to develop the spray-coating type HPFRCCs for safety protection and explosion-proof of the existing structures, the assessment results of the impact factors on the composite materials in accordance with the phases of paste, mortar and HPFRCCs respectively led us the following conclusions.

(1) The rheological property assessment result in the paste phase without admixing fiber shows that, in cases of FA and GGBFs, the plastic viscosity and the yield stress were decreased in accordance with the admixing rate, and, in case of SF, the plastic viscosity and the yield stress were rapidly increased after $10 \%$ of admixing rate.

(2) The rheological property assessment result in the mortar phase without admixing fiber shows that the type of aggregates and the particle sizes, in other word, the particle form and particle size, had a great impact on the plastic viscosity and the yield stress.

(3) The rheological property and mechanical property assessments in the HPFRCCs phase admixing fiber shows that VA had more effect than SP in terms of the liquidity and fiber dispersion in accordance with the chemical admixtures dose, however, it was considered that the strength should be supplemented by using the deforming agents in accordance with the decreased strength when using VA. 
(4) It is judged that the study results herein will help us to control the qualities of the spraycoating features, liquidity, fiber dispersion etc. suitable for the conditions of the construction and the field through reflecting the influence factors of the composite materials in each phase of paste, mortar and HPFRCCs in the development of the spraycoating type HPFRCCs reinforced with the safety protection and explosion-proof for the existing structures in the future.

\section{References}

1. Li, V. C.; Wang, S.; and Wu, C., Tensile Strain-hardening Behavior of PVA-ECC. ACI Materials Journal 2001, 98(6), 483-492.

2. Kim, Y.Y.; Kim, J.S.; Kim, H.S.; Ha, K.J.; Kim, J.K., Mechanical Properties of an ECC(Engineered Cementitious Composite) Designed Based on Micromechanical Principle. Journal of the Korea Concrete Institute. 2005, 17(5), 709-716.

3. Nam, J.S.; Kim, H.S.; Lee, I.C.; Miyauchi, H.; Kim, K.H., Evaluation on the Impact Resistant Performance of Fiber Reinforced Concrete by High-Velocity Projectile and Contacted Explosion. Journal of the Korea Concrete Institute. 2013, 25(1), 107-114.

4. Song, Y.J.; Yun, H.D., Tension-Stiffening and Cracking Behavior of 100 MPa Shrinkage-Compensated Ultra High-Strength Strain-Hardening Cement Composite(UHS-SHCC) Ties. Journal of the Korea Concrete Institute 2013. 25(4), 371-379.

5. Ranade, R.; Li, V.C.; Stults, M.D.; Heard, W.F.; Rushing, T. S., Composite Properties of High-Strength, High-Ductility Concrete. ACI Materials Journal 2013. 110(4), 413-422.

6. Kim, Y. Y., Development of a Sprayable Ductile Fiber Reinforced Cememtitious Composite(ECC) Based on Micromechanics and Rheological Control. Journal of the Korea Concrete Institute 2003. 15(4), 557-565.

7. Park, S.B.; Kim, J.S.; Kim, Y.W., Rheology Control of Cement Paste for Applying ECC Produced with Slag Particles to Self-Consolidating and Shotcreting Process. Journal of the Korea Concrete Institute. 2008, 20(1), 67-75. 
Table 1. Chemical compositions and physical properties of binder

\begin{tabular}{c|c|c|c|c|c|c|c|c|c}
\hline Type & $\begin{array}{c}\mathrm{CaO} \\
(\%)\end{array}$ & $\begin{array}{c}\mathrm{SiO} 2 \\
(\%)\end{array}$ & $\begin{array}{c}\mathrm{Al} 2 \mathrm{O} 3 \\
(\%)\end{array}$ & $\begin{array}{c}\mathrm{MgO} \\
(\%)\end{array}$ & $\begin{array}{c}\mathrm{Fe} 2 \mathrm{O} 3 \\
(\%)\end{array}$ & $\begin{array}{c}\mathrm{SO} 3 \\
(\%)\end{array}$ & $\begin{array}{c}\text { L.O.I } \\
(\%)\end{array}$ & $\begin{array}{c}\text { Specific } \\
\text { surface } \\
\text { area } \\
\left(\mathrm{cm}^{2} / \mathrm{g}\right)\end{array}$ & $\begin{array}{c}\text { Density } \\
\left(\mathrm{g} / \mathrm{cm}^{3}\right)\end{array}$ \\
\hline \hline OPC & 61.60 & 19.80 & 4.50 & 3.01 & 3.57 & 2.10 & 1.20 & 3,450 & 3.15 \\
\hline FA & 5.95 & 52.83 & 18.08 & 1.43 & 7.74 & 0.01 & 6.14 & 3,710 & 2.34 \\
\hline GGBFs & 34.95 & 31.85 & 14.55 & 5.63 & 0.59 & 2.97 & 0.60 & 4,070 & 2.82 \\
\hline SF & 0.39 & 93.8 & 0.31 & 0.42 & 0.83 & - & 2.80 & 200,000 & 2.18 \\
\hline
\end{tabular}

Table 2. Physical properties of aggregates

\begin{tabular}{c|c|c|c|c}
\hline Type & $\begin{array}{c}\text { Density } \\
\left(\mathrm{g} / \mathrm{cm}^{3}\right)\end{array}$ & F.M. & $\begin{array}{c}\text { Absorption } \\
(\%)\end{array}$ & $\begin{array}{c}\text { Unit Weight } \\
\left(\mathrm{kg} / \mathrm{m}^{3}\right)\end{array}$ \\
\hline \hline Standard sand & \multicolumn{4}{|c}{ KS L ISO 679} \\
\hline Quartz sand & 2.65 & \multicolumn{2}{|c|}{$60 \sim 150$ mesh, SiO2 95\% more than } \\
\hline River sand & 2.56 & 2.70 & 1.56 & 1,670 \\
\hline Sea sand & 2.57 & 2.96 & 0.80 & 1,719 \\
\hline Crushed sand & 2.54 & 3.02 & 1.17 & 1,739 \\
\hline
\end{tabular}

Table 3. Physical properties of fiber

\begin{tabular}{c|c|c|c|c|c}
\hline Type & $\begin{array}{c}\text { Length } \\
(\mathrm{mm})\end{array}$ & $\begin{array}{c}\text { Diameter } \\
(\mu \mathrm{m})\end{array}$ & $\begin{array}{c}\text { Tensile } \\
\text { strength } \\
(\mathrm{MPa})\end{array}$ & $\begin{array}{c}\text { Young's } \\
\text { modulus } \\
(\mathrm{GPa})\end{array}$ & $\begin{array}{c}\text { Density } \\
\left(\mathrm{g} / \mathrm{cm}^{3}\right)\end{array}$ \\
\hline \hline PVA & 8 & 39 & 1600 & 40 & 1.30 \\
\hline
\end{tabular}

Table. 4 Experiment variable and evaluation item

\begin{tabular}{|c|c|c|c|}
\hline Type & & Experiment variable & Evaluation item \\
\hline \multirow[b]{2}{*}{ Paste } & Type of binder & OPC, FA, GGBFs, SF & Rheology \\
\hline & Mixing ratio of binder & $\begin{array}{c}\text { OPC } 100 \text { (Vol.\%) } \\
\text { FA 10, 20, } 30 \text { (Vol.\%) } \\
\text { GGBFs 15, 30, } 45 \text { (Vol.\%) } \\
\text { SF 5, 10, } 15 \text { (Vol.\%) }\end{array}$ & Rheology \\
\hline \multirow{2}{*}{ Mortar } & Type of fine aggregate & $\begin{array}{l}\text { Standard sand, Quartz sand, River sand, Sea } \\
\text { sand, Crushed sand }\end{array}$ & Rheology \\
\hline & $\begin{array}{l}\text { Grading of fine } \\
\text { aggregate }\end{array}$ & F.M. $1.80,1.95,2.32,2.69,3.06,3.43,3.61$ & Rheology \\
\hline HPFRCCs & $\begin{array}{l}\text { Dosages of chemical } \\
\text { admixtures }\end{array}$ & $\begin{array}{l}\text { SP } 0.9,1.2,1.5,1.8,2.1(\%) \\
\text { VA } 0.2,0.4,0.6,0.8,1.0(\%)\end{array}$ & $\begin{array}{c}\text { Fluidity } \\
\text { Rheology } \\
\text { Compressive strength } \\
\text { Flexural performance }\end{array}$ \\
\hline
\end{tabular}




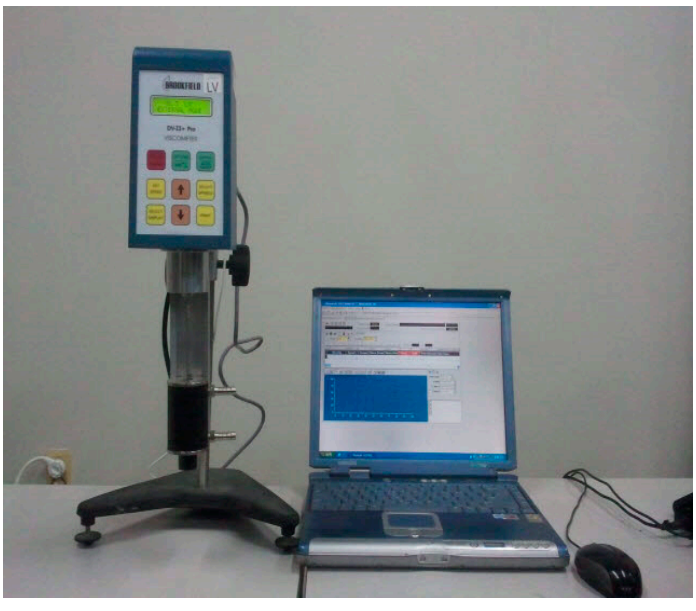

(a) Paste rheometer

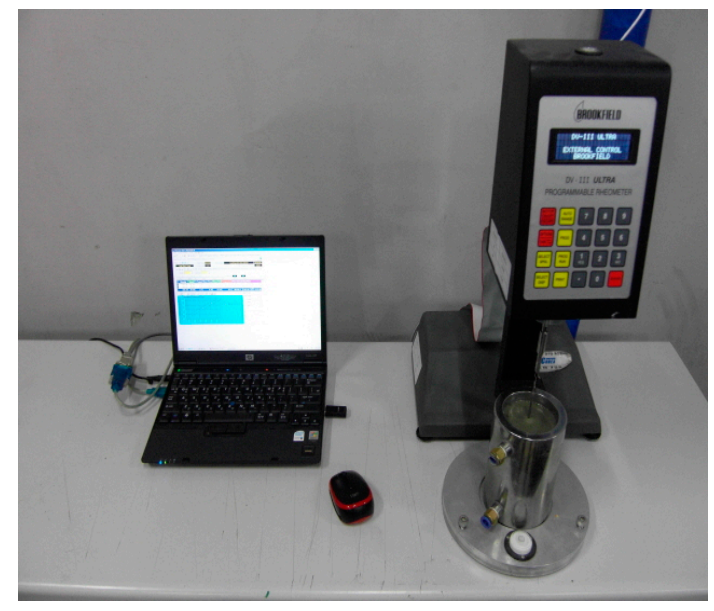

(b) Mortar rheometer

Fig. 1 Rheometer

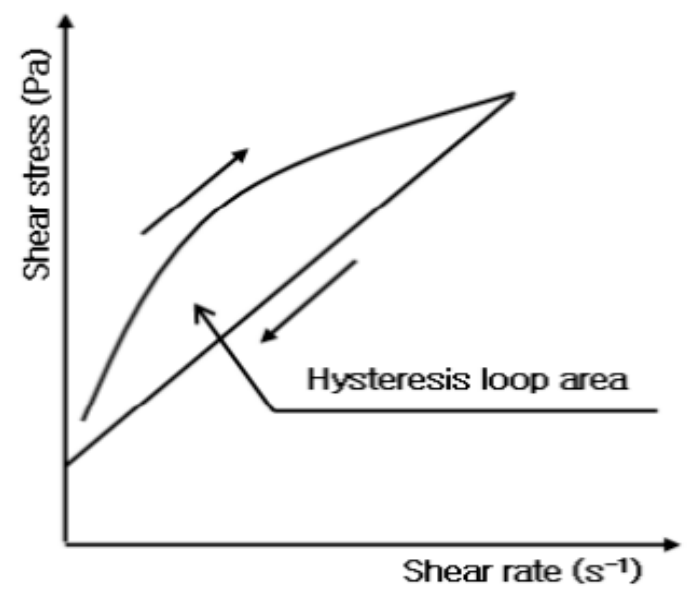

(a) Hysteresis model

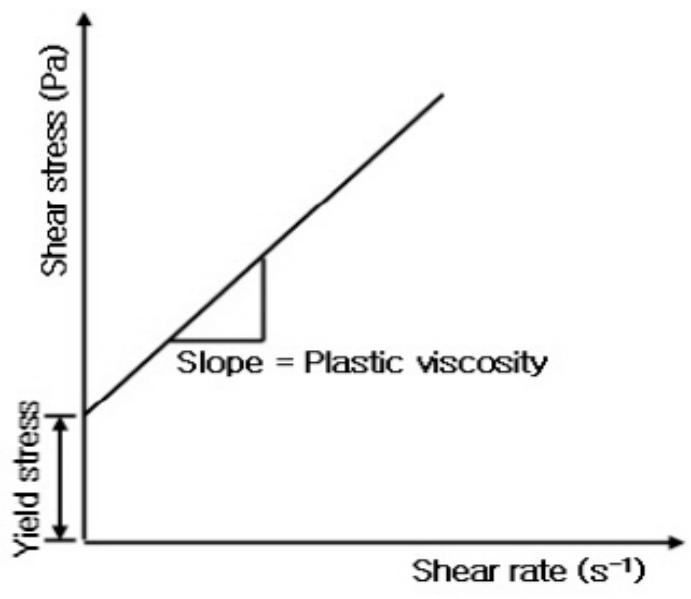

(b) Bingham model

Fig. 2 Analysis model of rheology

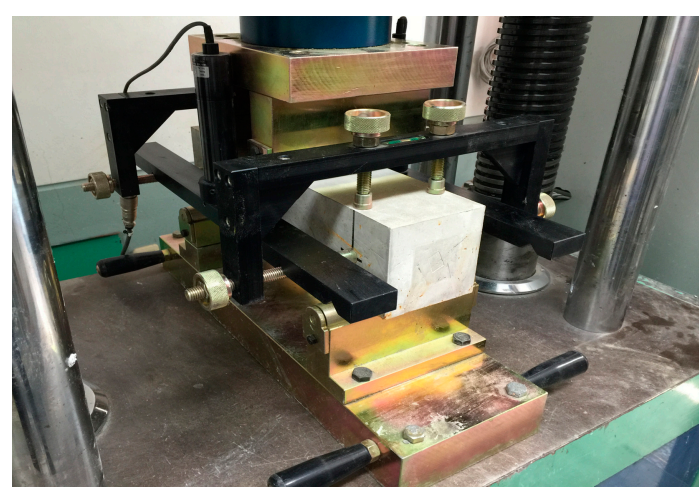

Fig. 3 Flexural performance measurement device 


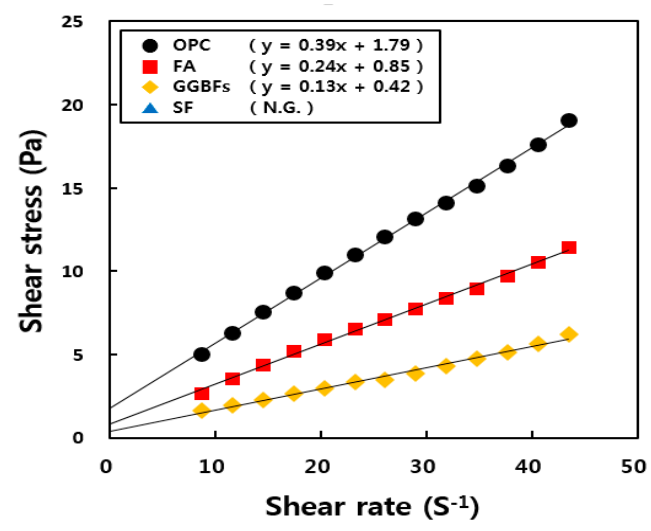

Fig. 4 Rheology properties according to type of binder

Table. 5 Rheology properties according to mixing ratio of binder

\begin{tabular}{c|c|c}
\hline Type & Plastic viscosity (Pa·s) & Yield stress (Pa) \\
\hline \hline OPC100 & 0.39 & 1.79 \\
\hline OPC90/FA10 & 0.36 & 1.39 \\
\hline OPC80/FA20 & 0.27 & 1.15 \\
\hline OPC70/FA30 & 0.20 & 0.72 \\
\hline OPC85/GGBFs15 & 0.30 & 1.05 \\
\hline OPC70/GGBFs30 & 0.24 & 0.43 \\
\hline OPC55/GGBFs45 & 0.19 & 0.16 \\
\hline OPC95/SF5 & 0.42 & 3.01 \\
\hline OPC90/SF10 & 0.63 & 5.62 \\
\hline OPC80/SF15 & 0.76 & 8.79 \\
\hline
\end{tabular}

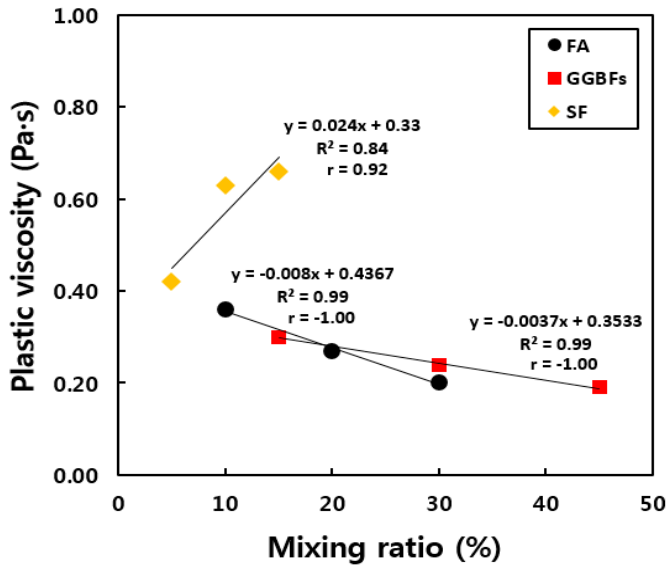

(a) Plastic viscosity

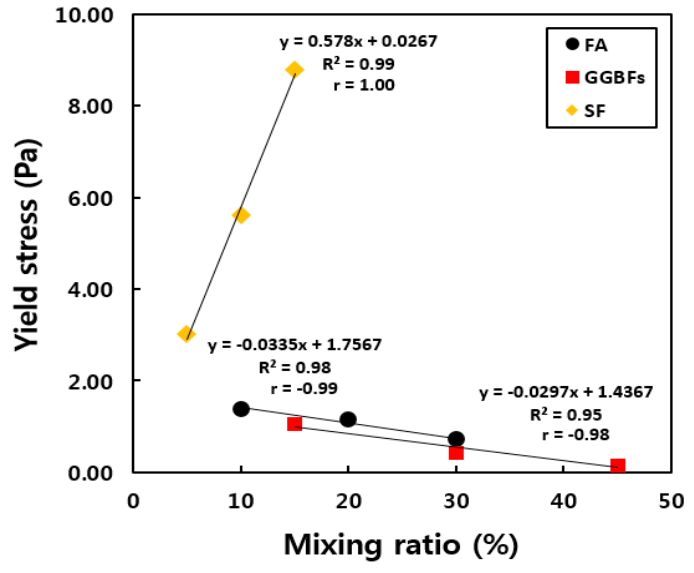

(b) Yield stress

Fig. 5 Correlation of Rheology according to mixing ratio of binder 


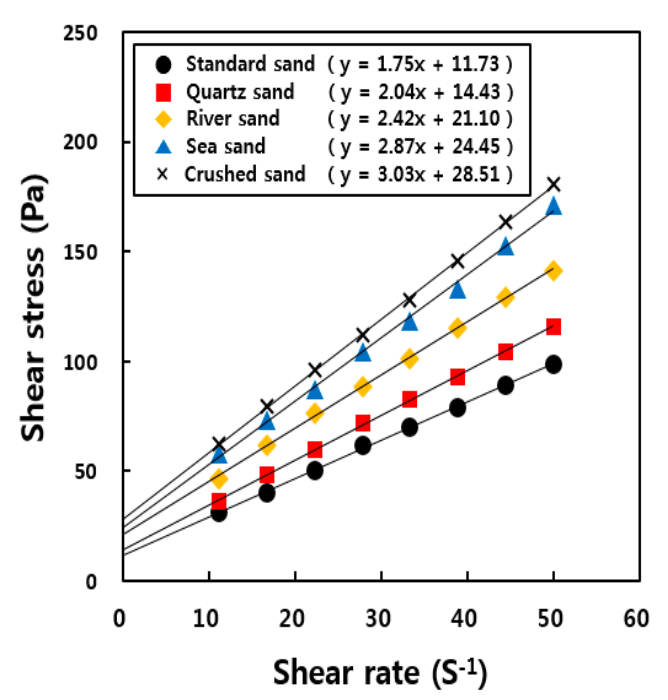

Fig. 6 Rheology properties according to type of fine aggregate

Table. 6 Rheology properties according to grading of fine aggregate

\begin{tabular}{c|c|c}
\hline Type & Plastic viscosity (Pa.s) & Yield stress (Pa) \\
\hline \hline F.M. 1.80 & 2.43 & 17.15 \\
\hline F.M. 1.95 & 2.31 & 16.52 \\
\hline F.M. 2.32 & 2.16 & 14.87 \\
\hline F.M. 2.69 & 1.91 & 12.86 \\
\hline F.M. 3.06 & 1.69 & 11.67 \\
\hline F.M. 3.43 & 1.40 & 10.01 \\
\hline F.M. 3.61 & 1.29 & 9.44 \\
\hline
\end{tabular}

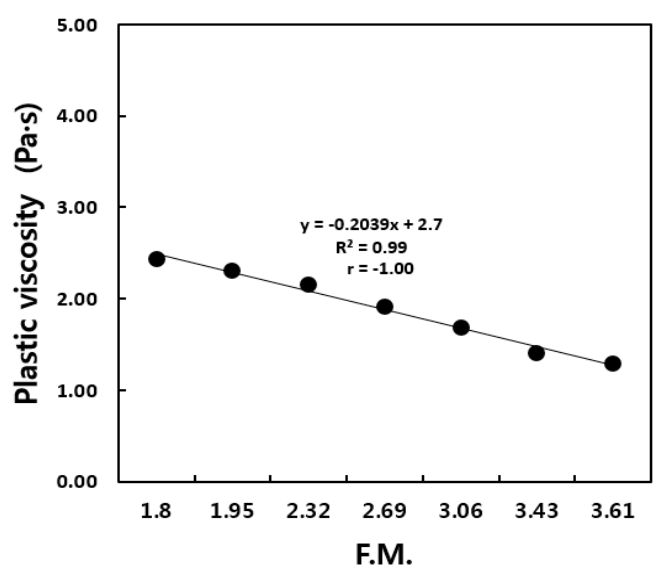

(a) Plastic viscosity

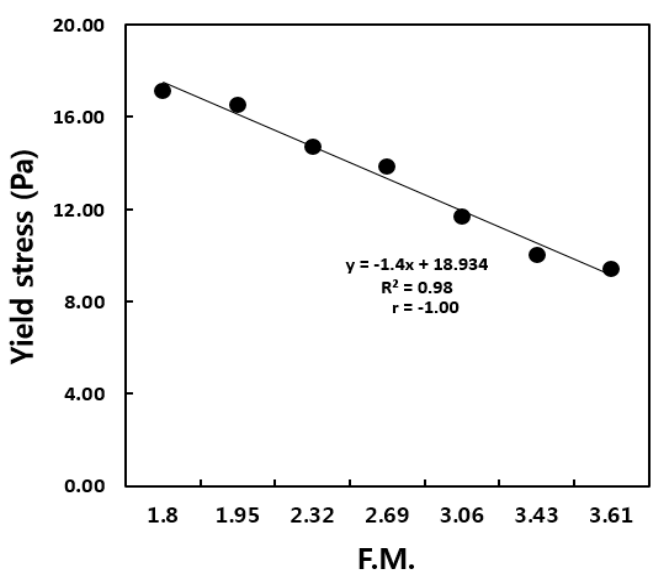

(b) Yield stress

Fig. 7 Correlation of Rheology according to grading of fine aggregate 


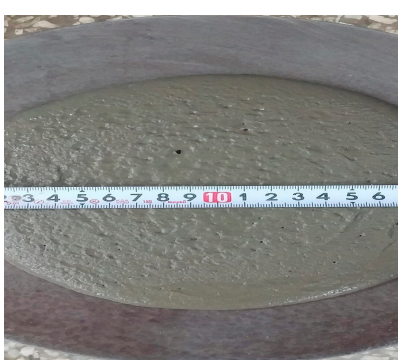

Plain

(SP 0.6\%, Fiber 0\%)

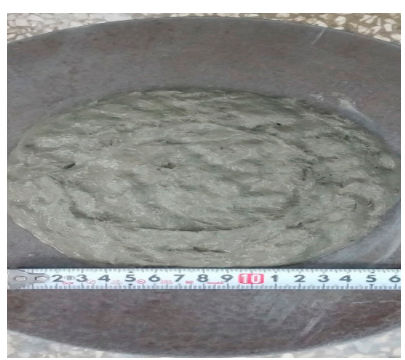

SP $1.5 \%$

(Fiber 2\%)

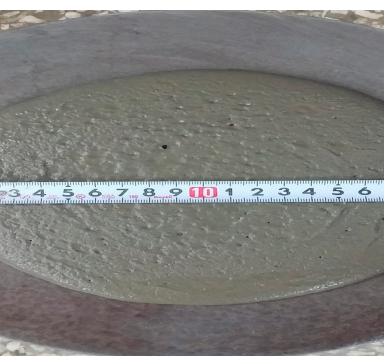

Plain

(SP 0.6\%, Fiber 0\%)

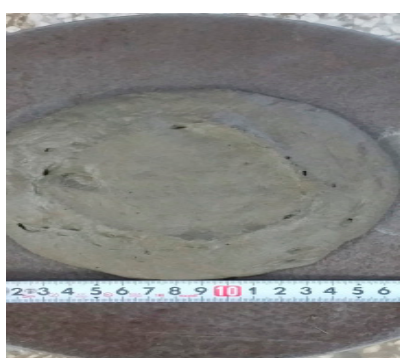

VA $0.6 \%$

(SP 0.6\%, Fiber 2\%)

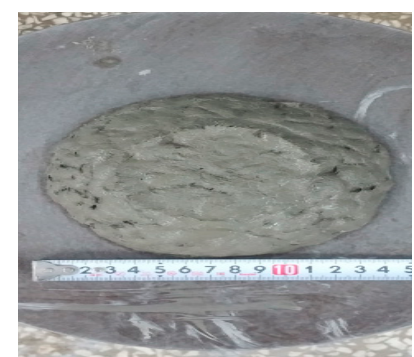

SP $0.9 \%$

(Fiber 2\%)

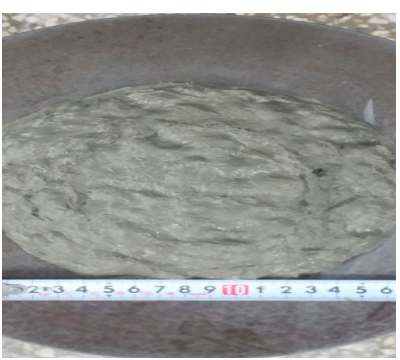

SP $1.8 \%$

(Fiber 2\%)

(a) $\mathrm{SP}$

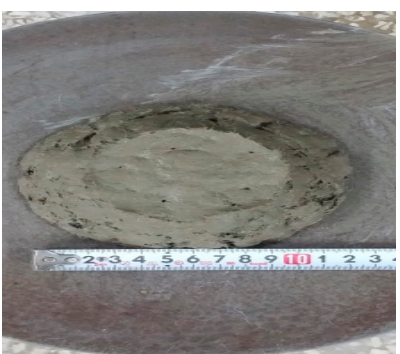

VA $0.2 \%$

(SP 0.6\%, Fiber 2\%)

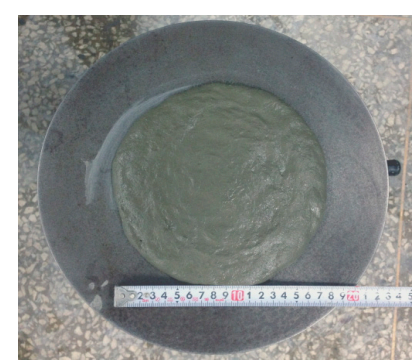

VA $0.8 \%$

(SP 0.6\%, Fiber 2\%)

(b) VA

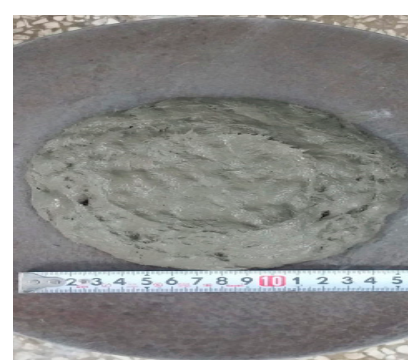

SP $1.2 \%$

(Fiber 2\%)

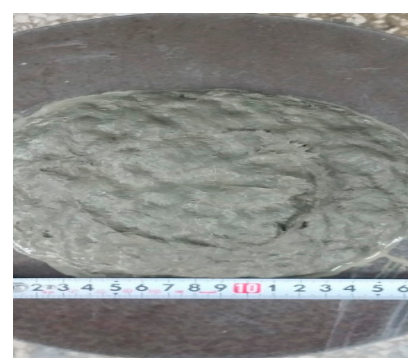

SP 2.1\%

(Fiber 2\%)

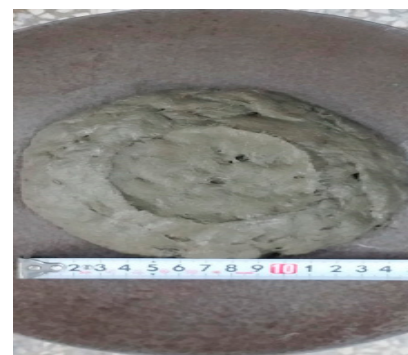

VA $0.4 \%$

(SP $0.6 \%$, Fiber $2 \%$ )

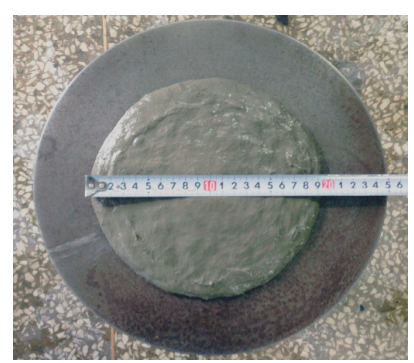

VA $1.0 \%$

(SP 0.6\%, Fiber 2\%)

Fig. 8 Flow according to dosages of chemical admixtures 


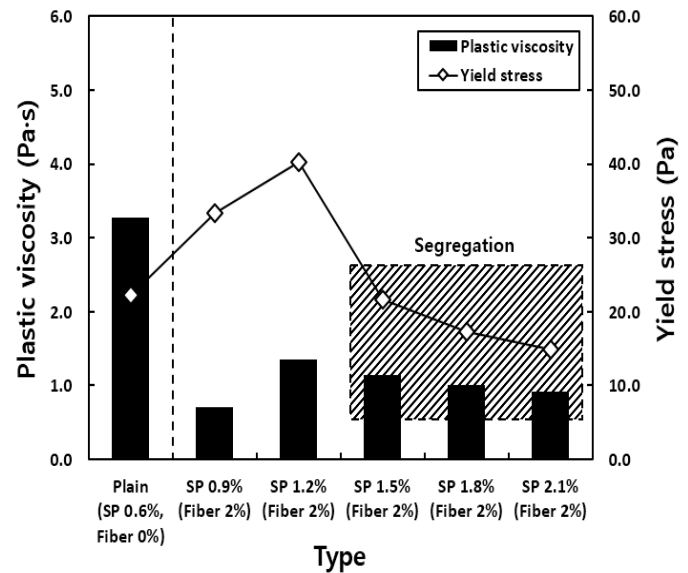

(a) $\mathrm{SP}$

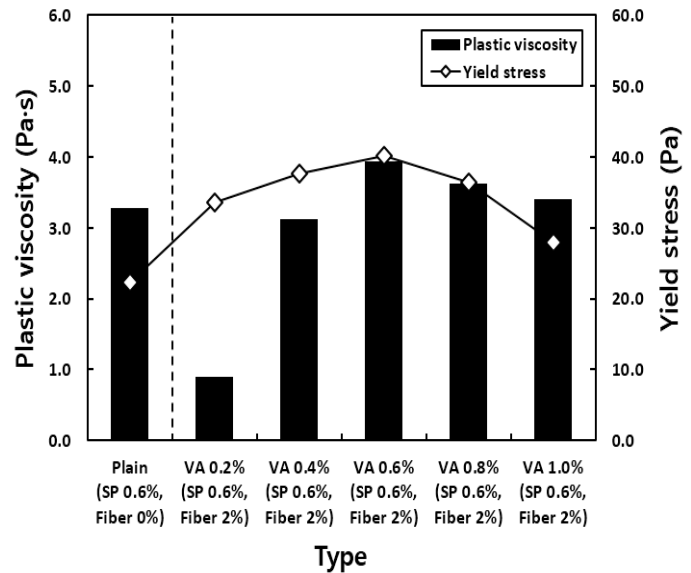

(b) VA

Fig. 9 Rheology properties according to dosages of chemical admixtures

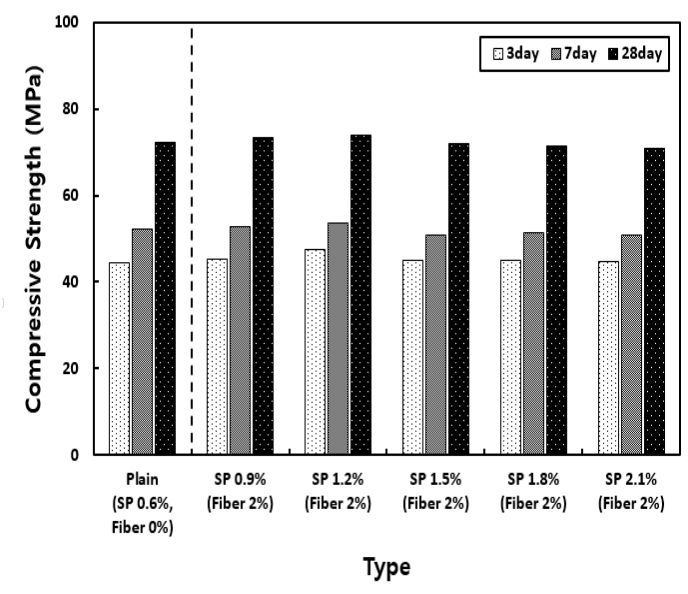

(a) $\mathrm{SP}$

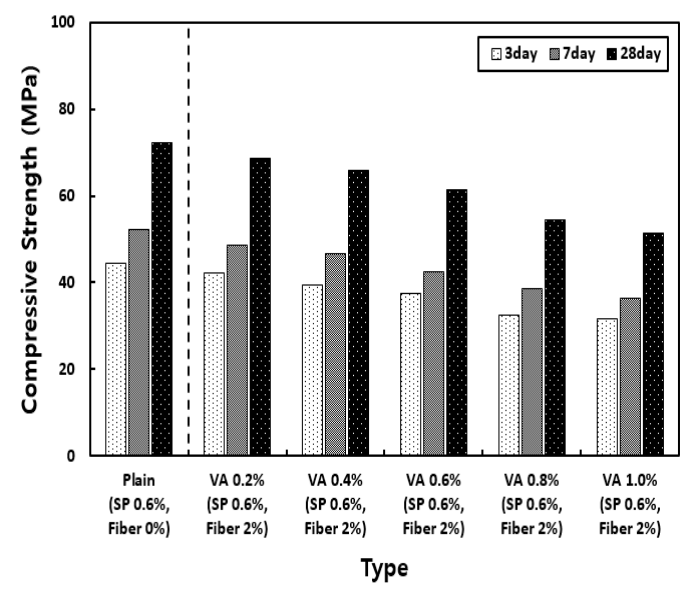

(b) VA

Fig. 10 Compressive strength according to dosages of chemical admixtures

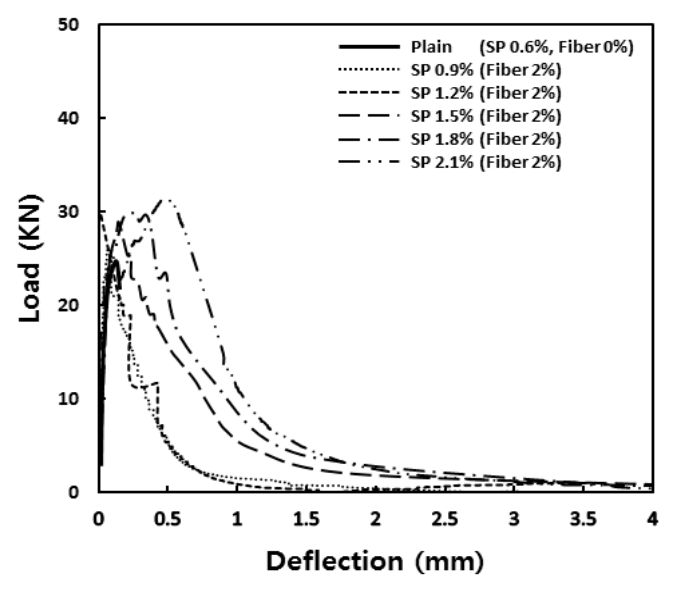

(a) SP

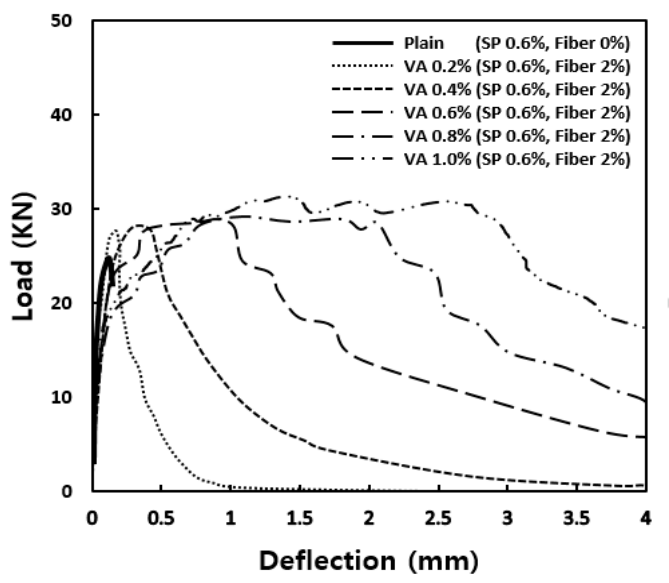

(b) VA

Fig. 11 Flexural performance according to dosages of chemical admixtures 
(C) 2017 by the authors; licensee Preprints, Basel, Switzerland. This article is an open access article distributed under the terms and conditions of the Creative Commons by Attribution (CC-BY) license (http://creativecommons.org/licenses/by/4.0/). 